Beneficence, Justice, and Health Care ${ }^{1}$

\title{
J. Paul Kelleher
}

Kennedy Institute of Ethics Journal 24(1) (March 2014)

[Author's note: The journal sent a pre-copy-edited version of this paper to the publisher, who then published it. The publisher blames the journal, and the journal refuses to pay the publisher's fee to correct the mistakes. The copy before you now is the copy-edited version that (among other things) fixes some bibliographical inaccuracies.]

\begin{abstract}
This paper argues that societal duties of health promotion are underwritten (at least in large part) by a principle of beneficence. Further, this principle generates duties of justice that correlate with rights, not merely "imperfect" duties of charity or generosity. To support this argument, I draw on a useful distinction from bioethics and on a somewhat neglected approach to social obligation from political philosophy. The distinction is that between general and specific beneficence; and the approach from political philosophy has at times been called equality of concern. After clarifying the distinction and setting out the basis of the equality of concern view, I argue that the result is a justice-based principle of "specific" beneficence that should be reflected in a society's health policy. I then draw on this account to criticize, refine, and extend some prominent health care policy proposals from the bioethics literature.
\end{abstract}

Must societies actively promote their members' health, rather than merely protecting them against the health-harming acts of others? This question can be broken down into two parts. The first part asks why health is important to individuals. Two leading answers are that health is important because of how it bears on individuals' well-being (Broome 2002) and because of how it bears on their effective opportunities (i.e. what they can effectively do and be in life) (Sen 1980; Daniels 1981). I will assume that at least one of these views is correct, and in this paper I seek to address the second part of the opening question. The second part asks what (if any)

\footnotetext{
${ }^{1}$ For comments and discussion on material included here, I would like to thank Dan Hausman, Gordon Hull, Win-chiat Lee, John C. Moskop, and participants at the 2013 Junior Scholars in Bioethics Workshop at Wake Forest University.
} 
normative principles account for a society's responsibilities to promote the health of its members, and what shape do those responsibilities take?

Many bioethicists and political philosophers believe that it must be a principle of justice that provides the key link between the importance of health to individuals and the healthpromoting responsibilities of society. But not everyone agrees. As Allen Buchanan has written, "The difficulty is that we may be much surer that someone ought not to lack a certain form of health care than we are about whether the ground of this judgment is a principle that structures our sense of justice or our sense of charity or beneficence or generosity" (1984, p. 57). And after struggling to find a sound principle of justice that guarantees a decent minimum of health care to all, Buchanan famously concludes that a decent minimum should be provided as a matter of law, but that the normative basis for this draws most heavily upon considerations of harm-prevention and prudence, and upon principles of enforceable beneficence and charity, rather than principles of justice. Buchanan concedes that individuals do not in general possess a moral right that their society actively promote their health, because individuals do not possess rights to beneficence. However, Buchanan insists that this is not cause for dismay, since it nicely explains why we find it so difficult to be precise about what a decent minimum should include. For in his view (and indeed in the view of many theorists), duties of beneficence are "imperfect" duties, which "by their very nature ... are not precisely delineated" (p. 77) and which tolerate considerable leeway in deciding how and when to discharge them.

In this paper I too will defend the view that societal duties of health promotion are underwritten (at least in large part) by a principle of beneficence. But I will argue that this principle is a principle of justice, and that the duties it generates correlate with rights. In support of this argument, I will draw on a useful distinction from bioethics and on a somewhat neglected 
approach to social obligation from political philosophy. The distinction is that between general and specific beneficence; and the approach from political philosophy has at times been called equality of concern. After clarifying the distinction (section 1) and exploring the basis of the equality of concern view (sections 2 and 3), I argue that the result is a justice-based principle of "specific" beneficence that should be reflected in a society's health-related public policy. In section 4 I discuss ways in which this view should shape health policy. Despite endorsing some concrete conclusions, my discussion in this final section is admittedly vague. But as I shall argue, Buchanan was incorrect to associate vagueness with charity and precision with justice. When it comes to justice in health care, sometimes vague principles are all that moral theory has to offer. Section 5 concludes.

\section{GENERAL AND SPECIFIC BENEFICENCE}

I will understand beneficence as action that promotes another's interests for its own sake, and not merely because another's doing well is instrumentally useful for one's own purposes. It is important to distinguish this conceptual understanding of beneficence from two further moral claims. The first is the claim that there is some duty (or duties) to be beneficent. This is a claim I shall argue for. The second moral claim is that duties of beneficence (if they exist) are always duties of generosity or charity, and never duties of justice. This is a claim I reject.

Beauchamp and Childress draw a further distinction between general and specific beneficence. They write that specific beneficence "is directed at particular parties, such as children, friends, contractors, or patients. .. . By contrast, general beneficence is directed beyond special relationships to all persons" (2013, p. 205). This distinction is not uncontroversial. For instance, while Beauchamp and Childress draw heavily upon the moral framework of W. D. 
Ross, some of Ross's remarks suggest that he would bridle at the notion of "specific" beneficence. Ross claims that duties of beneficence are those that "rest on the mere fact that there are other beings in the world whose condition we can make better in respect of virtue, or of intelligence, or of pleasure" (1930, p. 21). This formulation clearly betokens Beauchamp's and Childress's notion of general beneficence. Ross further suggests that beneficence should be distinguished from moral requirements that derive from special relationships. He writes:

In fact the theory of "ideal utilitarianism" . . s seems to simplify unduly our relations to our fellows. It says, in effect, that the only morally significant relation in which my neighbours stand to me is that of being possible beneficiaries by my action. They do stand in this relation to me, and this relation is morally significant. But they may also stand to me in the relation of promisee to promiser, of creditor to debtor, of wife to husband, of child to parent, of friend to friend, of fellow countryman to fellow countryman, and the like; and each of these relations is the foundation of a prima facie duty, which is more or less incumbent on me according to the circumstances of the case. (p. 19)

When combined with Ross's understanding of beneficence, this passage in effect claims that there is more to morality than beneficence, and that this further content relates to our past actions and our special relationships. This gives some support to the view that "specific" beneficence is a misnomer: for Ross, it seems as if beneficence is always general beneficence whose rationale rests on "the mere fact that there are other beings in the world whose condition we can make better." Whatever might be called "specific beneficence" should, Ross suggests, be called something else.

In Bioethics: A Systematic Approach, Gert, Culver, and Clouser (GCC) also reject the notion of specific beneficence. In response to Beauchamp and Childress, GCC write

[Beauchamp and Childress] are clear that doctors, nurses, and others in the health care field have specific duties to their patients that are determined by their profession and by the practices of their specific institution. To lump these varied and detailed professional duties together with the misconceived "general duty of beneficence" and place them all under one principle of beneficence is to substitute a slogan for substance. (Gert, Culver, and Clouser 2006, p. 120) 
GCC here press two objections to Beauchamp and Childress's discussion of beneficence. First, GCC do not agree that general beneficence is a genuine moral obligation. In their view, it is better categorized as a moral ideal, which grants persons the "choice in deciding when to follow [it] and with regard to whom" (p. 115). Second, GCC hold that when there is a genuine duty to promote another's interests, that duty will come from some more specific relationship (e.g. the doctor/patient relationship), and it should therefore not be classified as a form of beneficence at all. Thus in one respect GCC are closer to Ross than are Beauchamp and Childress, and in another respect GCC are farther from him. GCC are closer to Ross insofar as they distinguish sharply between the morality of beneficence and the morality of special relationships; but they are farther from Ross insofar as GCC refuse to speak of duties or obligations of beneficence at all.

Since I intend to endorse justice-based duties of specific beneficence that have their basis in special relationships, I must reject the view, explicit in GCC and implicit in Ross, that the only genuine form of beneficence is general beneficence. To begin making my case, I note first that others in the Rossian tradition are quite willing to speak of duties of beneficence that arise out of special relationships. For example, the leading intuitionist philosopher in the Rossian tradition, Robert Audi, writes

I begin by speculating with a notion of autonomy that might be considered broadly Kantian ... ., but also might be viewed as Rossian insofar as it takes duties to others to arise in specific relationships. ... On the radical autonomy view, we do not have a duty of beneficence unless we autonomously incur it. We often do incur it, of course, and in at least two ways: explicitly, say by promising to do good deeds, and implicitly, by some other free undertaking or commitment. (2004 p. 95)

For Audi, then, the notion of specific beneficence is not conceptually incoherent, since it is not incoherent to speak of a duty of beneficence arising out of a specific deed or relationship. Still, 
even if Audi is correct that the notion is not incoherent, it is clearly a separate question whether it is theoretically useful to speak in terms of specific beneficence.

In my view, there are indeed good theoretical reasons to retain and employ the concept of specific beneficence. For one thing, many special duties appear to require the cultivation and exercise of a disposition to promote another's interests or good. Since "beneficence" is already a perfectly good term to characterize action of that sort, I see no reason to avoid it simply because the relevant duty has its basis in a special relationship. Second, we can easily give further texture to the distinction between duties of general beneficence and duties of specific beneficence by saying that only the latter correlate with claims. A child, for example, has a claim on the beneficence of her parent. By contrast, while it may be true that I would have genuine moral reasons to display beneficence toward each of a billion intelligent creatures discovered on Venus, GCC are arguably correct that none of them can invoke a corresponding claim against me. ${ }^{2}$ (This conclusion might not follow in certain well-defined cases of nearby rescue, but I lack the space to explore that possibility here. ${ }^{3}$ ) Thus, we can say that general beneficence is the beneficence I do or should display toward those who nevertheless do not have a claim to it, whereas specific beneficence is beneficence I do or should display toward those who do hold a claim to it. Moreover, once the idea of claims to beneficence is introduced, it is natural to allow that different special relationships generate claims of different strengths. For example: other things equal, a friend's claim on my beneficence is arguably weaker than my child's.

If, as I believe, these conceptual distinctions are useful and plausible, they can be used to respond to GCC's claim that "[t]o lump these varied and detailed professional duties together with the misconceived 'general duty of beneficence' and place them all under one principle of

\footnotetext{
${ }^{2}$ The Venus example is Thomas Pogge's (1999).

${ }^{3}$ Beauchamp and Childress 2013 discusses rescue cases in more detail (see pp. 206-209).
} 
beneficence is to substitute a slogan for substance." GCC may be right that there is no "one principle of beneficence" that stands above a duty of general beneficence and duties of specific beneficence. But there does not need to be such a "master" principle of beneficence in order for there to be discrete and more narrowly tailored principles of beneficence. One of these can be a general principle of beneficence (which generates either an ideal or a duty), while others can be more specific, having their basis in special relationships. Of course, not all duties stemming from special relationships will be duties of beneficence. Some, for instance, will simply be duties of fidelity that stem from a promise to do this or that quite specific action. But other duties stemming from special relationships are clearly duties that impose less discriminating demands, demands that require one first to assess what is in another's interests and then to pursue a course of action that substantially promotes those interests. The demands of parenthood are again a good example here. In these latter cases, I see no conceptual or theoretical impediment to calling

these duties what they appear to be: duties of beneficence aimed at specific individuals.

\section{SPECIFIC BENEFICENCE AND EQUALITY OF CONCERN}

I have defended Beauchamp and Childress's distinction between general and specific beneficence, and I suggested that different duties of specific beneficence have their basis in different special relationships and correlate with claims of differing strengths. (I will say more about what it means in practice to have a claim to beneficence in section 4.) With these concepts and distinctions in hand, we can describe Buchanan's position on rights to health care in slightly different terms from those he used. In Buchanan's terms, his approach to justifying a legal right to a decent minimum of health care was pluralistic: it sought to combine (1) "arguments from special (as opposed to universal) rights to health care," (2) arguments about harm-prevention and 
prudence, and (3) arguments for enforceable general beneficence (Buchanan 1984, p. 66). I want now to argue that the first set of arguments—arguments from so-called "special rights"- suggest that justice generates at least some duties of specific beneficence.

Buchanan gives three examples of what he has in mind when he speaks of "special" rights to health care. First is the right that certain individuals posses by virtue of being disadvantaged by historical injustices. Second is the right acquired when one has sustained unjust harm from specific third-parties, such as pollution harms inflicted by corporations. Third and finally,

a strong moral case can be made for special rights to health care for those who have undergone exceptional sacrifices for the good of society as a whole - in particular those whose health has been adversely affected through military service. The most obvious candidates for such compensatory special rights are soldiers wounded in combat. (p. 67)

Note here that Buchanan seems to accord special rights only to those soldiers "whose health has been adversely affected through military service." In response it might be asked: why is special concern for soldiers not warranted by the mere fact that they stand ready to risk life and limb for the good of society? It strikes me that the commitment a solider makes to society does in fact warrant a broader concern for her than Buchanan admits. Accordingly, I believe we should say that the special relationship binding society and soldier grounds a social duty of specific beneficence toward the soldier. ${ }^{4}$ Moreover, soldiers can assert claims on the beneficence of the society they stand ready to defend. If that is right, then we should expand Buchanan's pluralistic view so that it can also lean on enforceable duties of specific beneficence that correlate with claims.

\footnotetext{
${ }^{4}$ Note, however, that the precise action required by duties of specific beneficence will depend partly upon background institutions and established expectations. As Dan Hausman has suggested to me, if there were a social norm that soldiers' families were to use the soldiers' combat pay to address injuries, then a demand for further public assistance may be unjustified. But such a social norm will itself be justified only if combat pay is set from the beginning at a level high enough to reflect the specific beneficence that society owes to the soldier.
} 
Buchanan does not say explicitly whether he thinks a soldier's special right to health care is a right grounded in justice. But his discussion points in that direction, for he strongly distinguishes between special rights and beneficence, and it is only the latter that he associates with charity and generosity (rather than justice). What, then, shall we say about the less discriminating duty of specific beneficence I have claimed is owed to all soldiers (and not just those who are wounded in combat)? Is it a duty of justice? This of course turns on what justice is, and that is a hard and contentious question. Nevertheless, many theorists accept John Stuart Mill's view that “Justice implies something which it is not only right to do, and wrong not to do, but which some individual person can claim from us as his moral right" (Mill [1861] 2006, p. 102 [chap. 5, para. 15]). If, therefore, a non-battled-tested soldier does in fact possess a claim on society's beneficence, then the corresponding social duty is arguably one of justice. To be fair, Mill does say in his very next sentence that "No one has a moral right to our generosity or beneficence, because we are not morally bound to practise those virtues toward any given individual." But by "beneficence" Mill here means "general beneficence," and thus even if he is correct it does not follow that there are no rights to what we are now calling specific beneficence.

Suppose we agree that each soldier has a justice-based claim to the specific beneficence of his or her larger society or political community. Might there be a further case for concluding that each member of society, whether a solider or not, has a similar claim? Buchanan apparently thought not, citing the "exceptional sacrifice" that only people like soldiers make. This skepticism about "scaling up" specific beneficence is, I suspect, shared by many other bioethicists and political philosophers who prefer to ground enforceable, society-wide obligations in quite different principles of distributive justice. There is, however, one line of argument from contemporary political philosophy that argues for such a scaling-up, and it is one 
that I find attractive. This line of argument has not, however, been articulated in terms of obligatory specific beneficence toward others. Rather, it has been put in terms of a political community's obligations of equal concern for members of society. A view along these lines has been separately defended by political philosophers Ronald Dworkin (in his later work) and Richard W. Miller. According to Dworkin, "[e]qual concern is the sovereign virtue of political community," for "[n]o government is legitimate that does not show equal concern for the fate of all those citizens over whom it claims dominion and from whom it claims allegiance" (2002, p. 1). Similarly, Miller claims that "Equal concern is the more appropriate standard [of social justice] because it better reflects the moral significance of democratic citizenship. For equal concern ... expresses the proper valuing of the institutional loyalties on which a well-ordered democracy depends" (2002, p. 298).

I will examine the arguments underlying these claims in more detail in the next section. But before I do so, I want to establish the tight conceptual connection between what Dworkin and Miller refer to as concern for others and what I have been calling specific beneficence. Miller makes this connection plain when he explains that the duties of concern he is arguing for are duties to show "special loyalty to [fellow citizens], displayed in special concern for their needs" (2010, p. 43; emphasis added). For Dworkin's part, things are complicated by the fact that in his early writings, Dworkin often used the phrase "equal concern and respect" to refer to a highly abstract moral standard that virtually all political theorists, including libertarians, expect a just society to meet (see, e.g., Dworkin 1978, p. 180). But in later writings, Dworkin was clear that by equal concern, he no longer intends the abstract and largely formal notions of equal moral status or equal protection under the laws, but rather a more robust moral standard requiring the promotion of individuals' substantive interests. For example, he writes: 
Imagine that a family is about to buy a new house and wishes to buy the house with the largest aggregate bedroom space, measured in overall square feet, that it can afford. Does it show equal concern for its members if it buys the house with the largest average bedroom size even though one bedroom, which it knows will be occupied by the youngest child, is miserable dark and insufferably small? $(2008$, p. 102)

Dworkin's answer to this rhetorical question is clearly "no," and he suggests that this way of thinking connects up with the proper way to think about social justice. For he asks, "Given the complex and dramatic impact of a political settlement [i.e. a given socio-economic institutional arrangement] on citizens' individual resources, what choice of political settlement treats citizens with equal concern? What choice would the fair-minded parent of them all make, for example?" (2008, p. 99; emphasis added). Now of course many will object to Dworkin's analogy between a just political community and a fair-minded parent; I too find the analogy problematic. But for our purposes here, what is relevant is that for Dworkin, the social obligation to display equal concern is akin to a parent's obligation insofar as it is a substantive obligation to actively promote certain individuals' interests and good. It is not, therefore, merely the formal ideal of treating like cases alike, for that formal ideal could be satisfied by a bedroom-allocation rule that says "The youngest child, whoever he or she happens to be, shall get whatever bedroom remains after all older members of the family have made their choice."

Suppose, then, that Dworkin's and Miller's so-called duties of concern are indeed properly interpreted as duties of specific beneficence toward fellow citizens. We now must ask where those duties come from. What justifies them?

\section{JUSTIFYING EQUAL CONCERN}

Here is Dworkin's main argument for why a duty of equal concern is at the heart of social justice: 
We extract people's money or property through taxes, and we put them in jail or even, in our country, kill them when they do not do what we command. We not only do all this but claim a right to do it: we expect our fellow citizens to treat our collective demands as creating not just threats but moral obligations, the demanding moral obligation to obey our law. No single individual has any such power over other individuals. Our government claims all of it. (2008, p. 95)

A legitimate government must treat all those over whom it claims dominion not just with a measure of concern but with equal concern. (p. 97)

Dworkin here grounds a political community's duty to display equal concern toward its members in the coercively enforced commands issued by the community (or by its official agents). He claims that the community's commands are illegitimate unless they are accompanied by the display of a robust and equal measure of concern for each member. Yet even if Dworkin is correct in this, so far he has stated only a necessary condition of legitimate coercion, not a sufficient condition. After all, it would surely be objectionable for one society to invade and conquer another, even if afterwards it displayed the same degree of positive concern for those it conquered as it displays for its own members. So what further condition gives a political community the right to issue coercively-backed commands in the first place? Dworkin imagines being asked a similar question by a laissez-faire libertarian. In response he says:

Of course we can, if that is what the majority of us wish, create a minimalist government with few powers to do anything except maintain a police force and armies and raise only the taxes necessary to those limited powers. But ... we would therefore have the responsibility of showing how our decision to create a minimal state, when we might have created a government with much greater powers to help our poorer fellow citizens, treats all of us with equal concern. (2008, p. 100)

This still seems to beg the question. Dworkin claims that a minimalist government would fail to show adequate concern for its members, but he still does not explain where these robust duties of concern come from in the first place. The welfare state institutions that Dworkin wants to justify are required only if robust duties of concern already exist. But Dworkin has not given us reason 
to think these duties exist prior to the existence of the robust political relationships that a welfare state introduces.

This is a problem that Miller explicitly takes up in his own concern-based approach to social justice. Miller writes:

Because of the dependence of political duties of concern for compatriots on the nature of their shared political life, I will concentrate on one special case, the exercise of the functions characteristic of government in modern developed countries. . . . Prior to investigating the moral consequences of this state activity, the modern state's engagement in such functionings must be justified. . . One can create a broad enough justification by exploiting a grain of truth in the argument from mutual benefit. In modern circumstances, every compatriot's rational self-interest supports an extensive set of government tasks, shaping compatriots' prospects of self-advancement in profoundly important ways. (Miller 2010, pp. 40-41)

So whereas Dworkin moves from the idea of robust concern to the justification of more-thanminimal governmental functionings, Miller moves from the idea of more-than-minimal governmental functionings to the requirement of robust concern. And to get the argument off the ground, Miller claims that the more-than-minimal government functionings are initially justified by reference to the rational self-interest of those who will be constrained by the resulting coercively enforced arrangements. As he puts it:

Libertarian defenders of capitalism say that they advocate the Nightwatchman State, implying that defense against burglars is the epitome of the state's legitimate functioning. But this restriction would be the death of modern capitalism. Everyone in a modern capitalist economy has a vital interest in state involvement, often with prolific public funding, in a variety of unnightwatchmanlike functions. (p. 43)

Part of what Miller refers to here is what the political scientist Nathan Kelly calls "marketconditioning" institutions (Kelly 2009, p. 18). These include the central bank's role in setting the key price in the entire economy, the interest rate; the central bank's role as lender of last resort; the state's bestowal of limited liability to corporate entities; and government granted monopolies in the form of patents. Very few libertarians argue seriously for abolishing these particular 
market-conditioning institutions. Yet neither it is plausible to claim that individuals have a natural right to these devices of government. (How plausible is the claim that there's a natural right to twelve years of market exclusivity for an invented product, after which competitors are free to copy one's idea without any compensation whatsoever?) Rather, what justifies these governmental functions is that they are immensely effective tools for promoting the common good, conceived of as individuals' similar yet separate interests in a political stability and economic prosperity.

In addition to the major market-conditioning functions of government, Miller highlights further "unnightwatchmanlike" choices that will typically be reflected in the public policy of a prosperous democratic state. For example, there will likely be policies that answer such questions as "Under what conditions is a contract to provide skilled services marred by inadequate information about competence on the part of the buyer?" and "Under what circumstances does someone's assertion of exclusive control over land or raw materials give rise to a right, and how extensive, permanent and transferable are these rights?" (p. 41). All of these policy issues cited so far involve questions to which it is in the interest of everyone to have settled answers. Yet any answer specific enough for public policy will also be rejected by many. This leads to the move that distinguishes Miller's argument from Dworkin's. For when public policy does impose determinate answers on a wide range of policy questions, each citizen inevitably faces what John Rawls termed "strains of commitment" (1971, sect. 29). These are the reasonable and understandable psychological strains that attend living under laws and policies one disagrees with or finds otherwise burdensome. According to Miller, it is these common yet poignant strains - what he called the strains of "institutional loyalty" - that generate further duties of concern in the form of duties to value one another's "loyalty to the [political] project by 
showing special loyalty to [fellow participants], displayed in special concern for their needs" (2010, p. 43). Thus, for Miller, while a broad array of coercive policies can be justified by reference to members' self-interest, further coercive policies - those expressing robust concernare justified as the way responsible social cooperators acknowledge one another's mutual loyalty to a demanding and coercively structured political project.

I believe that this last argument for a political community's duties of concern for its members is superior to Dworkin's, and that it is compelling in its own right. Furthermore, the seeds of a view like this can be found in Beauchamp and Childress's discussion of how some duties of specific beneficence have their basis in the value of reciprocity. They write, "Reciprocity is the act or practice of making an appropriate and often proportional return" (2001, p. 213). And in a prior edition of Principles, Beauchamp and Childress claimed that "[M]any obligations of beneficence are appropriately justified by implicit arrangements underlying the necessary give-and-take of social life" (2001, p. 174). Of course, we have already seen that Beauchamp and Childress prescind from characterizing duties of specific beneficence as duties of justice, whereas Dworkin and Miller explicitly cast their discussions in those terms. But apart from that difference, Dworkin's and Miller's accounts can, I think, be viewed as fleshing out a line of argument that already exists in the bioethics literature but that is not as fully developed there.

At this point, it is necessary to address an important question triggered by Miller's account and by Beauchamp and Childress's description of reciprocity as the practice of making an "often proportional return." The question asks whether, by tying duties of concern and specific beneficence to loyal cooperation, a view like Miller's entails that those who contribute more should receive more than equal concern. After all, Miller's is an approach on which what 
one is owed (specific beneficence) is determined by what one does (give loyal and burdensome social cooperation). So shouldn't more go to those who give more? I want to offer four replies to this important question.

The first thing to note is that Miller's account underscores two features of modern democratic societies, and only the second of these is tied to individuals' social contributions. These two features again are: (1) the fact that a complex of rules governing social cooperation is coercively enforced by all upon all (this is the feature that Dworkin also highlights); and (2) the fact that life-long, coercively structured social cooperation inevitably brings poignant strains of commitment in its wake. The first feature focuses on the ways in which fellow citizens shape each other's lives and prospects by supporting coercive laws and policies. A reasonable claim here is that in helping to coercively structure another's life, one shows full respect for him only if coercion is accompanied by positive concern for how his life goes. Thus even if the premise referring to strains of commitment were removed, there would still be some basis for requiring specific beneficence toward those whose lives one helps to shape and structure.

Second, when we turn to the distinctive element of Miller's account that is tied to cooperation and contribution - the element concerning institutional loyalty and strains of commitment—one must be careful not to draw arbitrary distinctions between individuals' levels of contribution. For example, the account is decidedly not equivalent to an economistic approach that assesses social productivity by looking at wages as the quantifiable measure of individuals' economic contribution. ${ }^{5}$ That sort of approach ignores the pervasive reach of marketconditioning policies and the corresponding ways in which political stability and economic prosperity depend upon coercion, compliance, and cooperation at virtually all times and across

\footnotetext{
${ }^{5}$ For a recent defense of such a view, see Mankiw 2009. For cogent critique, see Sen 1985, Schweickart 2002, and Freeman 2011.
} 
virtually all spheres of life. It is arbitrary to single out just one sphere-market employment—as revealing one's total social contribution. Yet once one seeks to take account of all relevant spheres in which individuals' compliance and cooperation contribute to a well-functioning democratic society, it becomes difficult to claim that any one person's overall contribution is greater than any other's. For example, those who earn much less than others often face distinct strains of commitment just on that account.

Further, even when it does seem clear that certain people contribute more than certain others, a third consideration dulls that observation's moral force. For in most spheres of social life, one's ability to contribute is profoundly affected by the circumstances one finds oneself in, and the circumstances one finds oneself in often reflect historical injustice. This observation is particularly relevant for prominent cases involving those who violate rather than comply with coercively imposed laws and those who occupy prominent and important social and economic roles. If, for example, past discrimination, dispossession, or social marginalization affects one's abilities and willingness to participate in the morally important give-and-take of social and economic life, then it would be wrong (1) to hold the effects of that injustice against those who were adversely affected by it and (2) to praise the inordinate contributions of who were helped by it. If poverty begets disaffection (as it does) and if privilege begets social and economic capital (as it does), then a morally responsible political community will seek to calibrate the strength of its specific beneficence by attending both to social contribution and to potentially unjust background factors that render individuals differentially able to contribute in the first place. This conclusion suggests that a principle of specific beneficence must be combined with other principles of justice so that individuals are not held responsible for failing to make contributions when that failure is influenced by prior or ongoing injustice. These considerations 
pull the account back in the direction of equal concern, for if past injustice shapes individuals' contributions, then holding this against the victims of injustice is an unjust form of double jeopardy.

The fourth and final response to the claim that unequal contributions call for unequal concern acknowledges that some human beings, in particular those with profound cognitive disabilities, are mostly unable to contribute to society even under the most favorable conditions. But to acknowledge this is not yet to concede that such individuals are owed nothing under justice. The equal concern account, like Buchanan's own account of enforced general beneficence, purports to describe just one central source of enforceable societal obligation. As Buchanan stressed, there is good reason to seek to combine diverse sources of obligation to yield wider ranging demands. Whether other sources are available is a further question for moral theory that I cannot take up here. But it is nevertheless a mistake to reject a source of social obligation simply because it alone cannot achieve the full coverage that one might reasonably want.

I conclude, then, that there is a good case to be made for the egalitarian aspect of the equal concern account of societal duties of specific beneficence. My goal in this section has been to explain how Dworkin's and Miller's views connect up with the idea of specific beneficence, and how one might go about "scaling up" duties of specific beneficence to the societal level. For my part, when I reflect upon the nature of the positive, health-related duties I intuitively believe I have to fellow citizens, they do strike me as duties of beneficence, duties to show active concern for their interests and good. But since there are people around the world who are much worse off than most of my fellow citizens, the duties I intuitively feel I have to my compatriots must be ones of specific beneficence that, if genuine, justify focusing at least some efforts at home rather 
than abroad. This in turn calls for an explanation of why specific duties like this should exist in the first place. The line of argument I have set out grounds these duties in the ways in which I help to coercively shape the lives of my compatriots, and the ways in which I simultaneously benefit from their constrained cooperation and compliance.

\section{FROM SPECIFIC BENEFICENCE TO HEALTH CARE POLICY}

When it comes to justifying a legal right to a decent minimum of health care, the equal concern approach offers distinct advantages over Buchanan's general beneficence argument. Buchanan recognized that some might accept his argument's theoretical foundation while still rejecting his domestically-focused conclusion. For if the argument is largely predicated upon an enforceable duty of general beneficence, why focus on "the needy who dwell within the borders of a particular nation-state" (1984, p. 76)? In response, Buchanan claimed that there are no principled reasons to focus at home rather than abroad. Rather, there are "pragmatic" reasons that justify "a practical concession to the difficulties of being beneficent in an imperfect world" ( $p$. 76). By contrast, if within-border obligations are primarily underwritten by duties of specific beneficence, as the equal concern approach has it, then one would not have to rely so heavily on "pragmatic" reasons to give some deference to national needs. This would in turn strengthen the argument for a domestic decent minimum of health care.

The existence of specific duties of beneficence toward compatriots would also strengthen a recent argument for U.S. health reform made by David DeGrazia. DeGrazia claims that "Americans care deeply about achieving universal coverage, sensibly containing costs, protecting patient freedom, and preserving high-quality care." He adds that "There is more support for these goals, surely, than for any particular theory of justice” (2008, p. 32). DeGrazia 
concludes that it is unwise to invoke theories of justice in support of health reform; one should instead simply invoke the four items on DeGrazia's list of health care "goals." But then what is to be said when one discovers — as one surely will—disagreement over DeGrazia's first health care goal, that of achieving universal coverage? Here is DeGrazia's answer: "Not to consider universal coverage a high priority verges on the misanthropic" (p. 32). Another way to say this, of course, is that not to consider universal coverage a high priority is to lack minimal beneficence. But now consider the (admittedly quite unrealistic) scenario in which a misanthrope is successfully shamed by DeGrazia's charge of misanthropy and now wants to focus her newfound beneficence on more dire needs abroad. What can DeGrazia say to get this reformed person on board with the four U.S. health care goals? One thing he could say, if he accepts societal duties of specific beneficence, is that to neglect serious but less dire needs at home would amount to flouting distinctive duties to compatriots.

Suppose I am right that the equal concern account successfully establishes societal duties of specific beneficence. And suppose that, given my initial assumption of the importance of health for well-being and opportunities, there is a strong presumption in favor of providing a decent minimum of health care to all. What then should the decent minimum include? Buchanan's answer is that this question cannot be specified in detail prior to subjecting it to "some fair procedure for reaching a social decision" $(1984$, p. 78$)$. That is roughly my answer too, but Buchanan claims that only his view "can warmly welcome the lack of a principled specification." The equal concern view must, he suggests, "accept it begrudgingly as an embarrassing theoretical lacuna" (pp. 77-78). This is because on Buchanan's view, citizens' duties of beneficence are not duties of justice that correlate with rights, but are instead duties of charity that "are imperfect duties: by their very nature they are not precisely delineated" (p. 77). 
Is Buchanan right that the demands of equal concern, if they are demands of justice, must be precisely specifiable?

Earlier I quoted Mill who conceptually tied duties of justice to individuals' correlative claims. If the connection with claims is a hallmark of duties of justice, then social duties of specific beneficence fit the bill, for on the equal concern account each individual does have a strong claim on the beneficence of the political community as a whole. I do however admit that there will be a good deal of indeterminacy when moving from foundational demands of equal concern to their practical implementation. I see no way around that. But this is not the theoretical embarrassment Buchanan suggests it is. To use an illustrative example of Robert Audi's, justice in a democracy quite obviously demands periodic free elections, but justice is clearly not specific about the maximal time interval between them (p. 152). Given that justice must tolerate at least some vagueness, we need an argument before we should conclude that the equal concern view cannot follow Buchanan's own tack and rely upon a conscientious social dialogue to issue in more specific conclusions.

Still, perhaps one way to make at least some progress translating the equal concern rationale for specific beneficence into policy is to imagine free market arrangements and then to ask whether they strike us as adequately expressing the beneficence required by justice. If not, we can ask what change would remove the deficiency. Something akin to this procedure has been employed by theorists as diverse as Dworkin (1993) and the conservative legal theorist Charles Fried (1978). Dworkin and Fried each agree that free market arrangements might need correction with respect to the potentially unjust distribution of external resources (such as income and wealth). To address this, each asks his reader to assume that the distribution of external resources is perfectly just according to the reader's own criterion of what justice 
requires here. Dworkin and Fried then ask: would it then be just to simply let individuals choose their preferred level of insurance from the options that emerge in a free market for health insurance? Dworkin's answer is that such an arrangement fails to show adequate concern for those who will be denied affordable insurance because of health risks they are either born with or acquire through no fault of their own (2002, pp. 342-343; 2008, p. 114). Fried foresaw such an objection, and wrote:

there is nothing in the [free market] insurance proposal which assumes that expensive measures will not be available in the unlikely case that we need them: if the occasion of need is really very unlikely, then one ought to be able to purchase a very high level of protection for a small premium. If, on the other hand, the "need" is very likely to occur and very likely to be expensive-imagine some elaborate way to retard the effects of normal aging - then why should one complain if vast social resources are not made available for this purpose? (1978, p. 128)

The problem here is that Fried ducks the question at issue. The question is not whether social resources should be made available for a Peter Pan drug that keeps people young, but rather whether those who already have, say, cancer or diabetes - those whose risk is 100 percentshould face higher (and often prohibitively high) insurance prices just on that account. This question cannot be answered by noting, plausibly, that public subsidies for the Peter Pan drug would not be required by any reasonable approach to social beneficence. Rather, it seems fairly clear that a political community does not show even minimal beneficence toward a cancer victim if it justifies not helping him by citing an alleged analogy between him and the Peter Pan drugseeker. This supports the conclusion that free markets for insurance, even when corrected for unfair distributions of income, do not yet display due beneficence toward those who face high and costly health risks through no fault of their own. Some policy instruments-e.g. guaranteed issue, community rating, insurance mandates, and subsidies — will be required to ensure that 
those who need health care the most are not turned away by insurance companies' prices or policies. ${ }^{6}$

This line of argument connects the demands of specific beneficence to what Paul Menzel has recently called a Just Sharing Principle (JSP). A JSP requires at least some robust sharing of "the financial burdens of illness." On Menzel's version of the JSP, it requires that "[t]he financial burdens of medical misfortunes ought to be shared equally by the well and the ill alike, unless individuals can be reasonably expected to control these misfortunes by their own choices" (2012, p. 584). Menzel grounds his JSP in a more fundamental moral principle that he calls Equal Opportunity for Welfare (EOW), which says: "People should not be worse off [in terms of welfare] than others through no fault or voluntary choice of their own." EOW is thus a luck egalitarian principle. There are many versions of luck egalitarianism, but their common thread is the claim that inequalities are pro tanto unjust, unless they can be shown to result from the responsible choices of individuals. (Pro tanto here indicates that the injustice can be outweighed by other moral factors; for example, a policy that widens unchosen inequalities may nevertheless be all-things-considered just if the increase in inequality is morally outweighed by significant improvements in the well-being of the worst off.) Luck egalitarianism, therefore, sees (pro tanto) injustice in inequalities that result from "bad brute luck," but not in inequalities that can be traced to individuals' responsible choices or gambles. This approach stands in contrast to the beneficence-based view I have been exploring. For example, while it may be clear that proper beneficence does not require the provision of a Peter Pan drug (especially when there are so many other pressing needs in the population), it is not as obvious that beneficence can justly be withheld whenever individuals are responsible for their own plight. Indeed, a leading luck

\footnotetext{
${ }^{6}$ These are central coverage-related policy instruments in the Patient Protection and Affordable Care Act of 2010 , but they are certainly not the only way to achieve affordable universal coverage.
} 
egalitarian, Shlomi Segall, agrees that luck egalitarian principles like EOW can be unduly harsh on those who are nevertheless at fault for their serious health needs. Segall concludes that principles like EOW must therefore be supplemented by "a prior duty to meet basic needs, including medical needs" (2009, p. 75). Segall's social duty to meet basic needs has all the hallmarks of a duty of beneficence, and his reliance on it shows that luck egalitarianism is not the only basis available to underwrite a Just Sharing Principle. Distinct beneficence-based moral principles can play that role as well. In fact, concerns about the "harshness" of luck egalitarianism suggest that beneficence-based principles might be better suited to play that role than is a thoroughly choice-sensitive principle like Menzel's EOW. ${ }^{7}$

A beneficence-based approach to social obligation can also be used to criticize Menzel's JSP on a different score. As I noted, Menzel's JSP calls for equal sharing of the financial burdens of illness "by the well and the ill alike." But why call on the well, rather than on the well-to-do, to share burdens with the ill? Suppose Steve Jobs had lacked insurance when he was very sick. In that case, should a healthy 35 year old making $\$ 15,000, \$ 35,000$, or even $\$ 55,000$ per year be called upon to share the burdens of Steve Jobs' illness? That is seemingly what would be required by a principle enjoining equal sharing between the well and the ill. Yet it seems more plausible, and more consistent with the demands of beneficence, to require sharing between the rich and the ill. We should indeed care about what happens to Steve Jobs—-he has a claim on our beneficence too- but we must also be sensitive to the effects that a Just Sharing Principle would have on the interests of those who would be forced to help him. When the person needing help is rich enough to provide all available care for himself, it is unclear why any sharing at all is called

\footnotetext{
${ }^{7}$ I lack the space to discuss the difficult question of when individuals' responsibility for their own ill health lessens or eliminates others' duties of beneficence toward them. For further discussion of the socalled harshness objection to luck egalitarianism, see Anderson 1999 and Voigt 2007.
} 
for. ${ }^{8}$ Likewise, when those who are sick are also very poorly off in terms of income, it seems reasonable to finance social beneficence through progressive taxation (which falls more heavily on the rich) rather than through a mechanism that targets the resources of healthy people, regardless of their income.

Finally, let me stress that even if duties of specific beneficence do in fact ground social rights to health care, it does not follow that doctors have duties of specific beneficence toward their patients. As I have been understanding them, duties of beneficence are duties to promote another's interests or good or well-being, broadly construed. But physicians' duties should arguably be construed more narrowly, as duties to promote patients' health, rather than patients' well-being. To use an example I owe to Daniel Hausman, my physician has a stronger duty to help me gain access to a $\$ 50$ tetanus shot than she does to help me gain access to $\$ 50$ in cash. This is so even if I strongly and quite reasonably prefer the cash instead. So it must be stressed that my argument seeks to account for the fundamental duties of social justice that call for health-promoting social institutions. These fundamental duties can be duties of (specific) beneficence even if there are reasons to construe the downstream duties of physicians more narrowly.

In this section I have sought to tease out some policy implications of the beneficencebased view that emerged from sections 2 and 3. But I have also openly admitted that there is unavoidable vagueness both in the strength of morally required specific beneficence and in the proper manner of its display. Buchanan suggested that vagueness along these dimensions fits better with an approach that views the relevant moral principles as principles of charity rather than principles of justice. I do not agree. Sometimes the demands of justice are just as vague as

\footnotetext{
${ }^{8}$ Since Menzel's discussion is pitched at the level of moral principle, I am here ignoring strategic considerations such as those connected to the slogan, "A program for the poor is a poor program."
} 
the demands of charity, as was illustrated by Audi's example of the interval between free democratic elections. Thus while I do believe that individuals have assertable moral claims to societal beneficence, I do not believe that individuals can assert moral claims to specific amounts of health-related resources. Nevertheless, some Just Sharing Principles are more consonant with the equal concern account of specific beneficence than others, and I have suggested that a reasonable version of such a principle would justify public policy to shape health insurance markets and would call more upon the wealthy than on the healthy to share others' financial burdens of illness.

\section{CONCLUSION}

In this paper I have drawn on a distinction from bioethics and on an approach to social obligation from political philosophy to support the conclusion that political communities are under justice-based obligations of specific beneficence toward their members. Since I am forced to concede that these obligations are not as precisely specifiable as one would like, I sought (in section 4) to tease out some lessons for health policy that nevertheless strike me as consonant with the account I have set out. In particular, I agreed with Dworkin and Segall that duties of beneficence (Dworkin calls them duties of concern, Segall cites "basic needs") can underwrite a Just Sharing Principle justifying at least some government involvement in health insurance markets.

There are, however, many options in between a regime that only slightly improves upon the free market and a regime that is prepared to provide Fried's Peter Pan drug to anyone that wants it. Should I be embarrassed that I cannot say which regime in between these is most just? All I can say is that I have been as specific as I can see how to be at present. At any rate, I 
believe it is useful to sketch, even in a rudimentary way, a framework for justice in health care that provides an alternative (or supplement) to views grounded in luck egalitarianism (Menzel, Segall), general beneficence (Buchanan), or the simple avoidance of misanthropy (DeGrazia). One need not be a misanthrope to ask why one must take an especially active interest in the interests of certain others. The equal concern approach to justice in health care provides an answer, and it is an answer I think worth exploring further.

\section{ACKNOWLEDGMENTS}

For comments and discussion on material included here, I would like to thank Dan Hausman, Gordon Hull, Win-chiat Lee, John C. Moskop, and participants at the 2013 Junior Scholars in Bioethics Workshop at Wake Forest University.

\section{REFERENCES}

Anderson, Elizabeth S. 1999. What Is the Point of Equality? Ethics 109 (2): 287-337.

Audi, Robert. 2004. The Good in the Right: A Theory of Intuition and Intrinsic Value. Princeton, NJ: Princeton University Press.

Beauchamp, Tom L., and James F. Childress. 2001. Principles of Biomedical Ethics, 5th ed. Oxford: Oxford University Press.

- 2013. Principles of Biomedical Ethics, 7th ed. Oxford: Oxford University Press.

Broome, John. 2002. Measuring the Burden of Disease by Aggregating Well-Being. In Summary Measures of Population Health: Concepts, Ethics, Measurement and Applications, edited by Christopher J. L. Murray, Joshua A. Salomon, Colin D. Mathers, and Alan D. Lopez, 91-113. Geneva: World Health Organization. 
Buchanan, Allen E. 1984. The Right to a Decent Minimum of Health Care. Philosophy and Public Affairs 13 (1): 55-78.

Daniels, Norman. 1981. Health Care Needs and Distributive Justice. Philosophy and Public Affairs 10 (2): 146-79.

DeGrazia, David. 2003. Common Morality, Coherence, and the Principles of Biomedical Ethics. Kennedy Institute of Ethics Journal 13 (3): 219-30.

- - . 2008. Single Payer Meets Managed Competition: The Case for Public Funding and Private Delivery. Hastings Center Report 38 (1): 23-33.

Dworkin, Ronald. 1978. Taking Rights Seriously. Cambridge, MA: Harvard University Press.

_. 1993. Justice in the Distribution of Health Care. McGill Law Journal 38 (4): 883-98.

- 2002. Sovereign Virtue. Cambridge, MA: Harvard University Press.

_ 2008. Is Democracy Possible Here? Princeton, NJ: Princeton University Press.

Freeman, Samuel. 2011. Capitalism in the Classical and High Liberal Traditions. Social Philosophy and Policy 28 (2): 19-55.

Fried, Charles. 1978. Right and Wrong. Cambridge, MA: Harvard University Press.

Gert, Bernard, Charles M. Culver, and Danner K. Clouser. 2006. Bioethics: A Systematic Approach. Oxford: Oxford University Press.

Kelly, Nathan J. 2009. The Politics of Income Inequality in the United States. Cambridge: Cambridge University Press.

Mankiw, N. Gregory. 2010. Spreading the Wealth Around: Reflections on Joe the Plumber. Eastern Economic Journal 36: 285-98.

Menzel, Paul T. 2011. The Cultural Moral Right to a Basic Minimum of Accessible Health Care. Kennedy Institute of Ethics Journal 21 (1): 79-119. 
_ 2012. Justice and Fairness: A Critical Element in US Health System Reform. The Journal of Law, Medicine \& Ethics 40 (3): 582-597.

Mill, John Stuart. (1861) 2006. Utilitarianism. In The Blackwell Guide to Mill's Utilitarianism, edited by Henry R. West, 61-113. Oxford: Blackwell Publishing.

Miller, Richard W. 2002. Too Much Inequality. Social Philosophy and Policy 19 (1): 275-313.

- 2010. Globalizing Justice: The Ethics of Poverty and Power. Oxford: Oxford University Press.

Pogge, Thomas. 1999. A Global Resources Dividend. In Ethics of Consumption: The Good Life, Ethics and Global Stewardship, edited by David Crocker and Toby Linden, 501-30. Totowa, NJ: Rowman and Littlefield.

Rawls, John. 1971. A Theory of Justice. Cambridge, MA: Harvard University Press.

Ross, W. D. 1930. The Right and the Good. Oxford: Oxford University Press.

Segall, Shlomi. 2009. Health, Luck, and Justice. Princeton, NJ: Princeton University Press.

Sen, Amartya. 1980. Equality of What? In The Tanner Lectures on Human Values, vol. 1, edited by Sterling M. McMurrin, 195-220. Cambridge: Cambridge University Press.

—. 1985. The Moral Standing of the Market. Social Philosophy and Policy 2 (2): 1-19.

Schweickart, David. 2002. After Capitalism. Plymouth, UK: Rowman \& Littlefield.

Voigt, Kristin. 2007. The Harshness Objection: Is Luck Egalitarianism Too Harsh on the Victims of Option Luck? Ethical Theory and Moral Practice 10 (4): 389-407. 